\title{
A HIGH YIELD SYNTHESIS OF 1,2:5,6-DI-O-ISOPROPYLIDENE-D-MANNITOL
}

\author{
ELSON SANTIAGO DE ALVARENGA*, VÂNIA MARIA TEIXEIRA CARNEIRO, \\ FLAVIANO OLIVEIRA SILVÉRIO, WILLIAM ARGOLO SALIBA
}

Departamento de Química, Universidade Federal de Viçosa, Viçosa, Minas Gerais, Brasil

\section{ABSTRACT}

A HIGH YIELD SYNTHESIS OF 1,2:5,6-DI-O-ISOPROPYLIDENE-D-MANNITOL: A great improvement in the synthesis of 1,2:5,6-di- $O$-isopropylideneD-mannitol (2) using D-mannitol (1) as starting material, is described. The acetalation of $(\Delta)$ was performed in acetone in the presence of zinc chloride as catalyst to give ( $\underline{2})$ in $87 \%$ yield. Some studies on the acetal stability were carried out to explain the high yields. High field NMR spectra were obtained and assignment of all signals was accomplished with the aid of double irradiation, difference NOE and HETCOR spectra.

Keywords: D-mannitol, acetal, zinc chloride, acetalation, diacetonide

\section{INTRODUCTION}

Diols react with aldehydes, ketones, 2,2-dimetoxypropane and 2methoxypropene to give cyclic acetals. This reaction is frequently employed to protect diols because acetals are stable under various conditions and can be removed by hydrolysis in the presence of acid. The preparation, chemistry, and physical properties of carbohydrates cyclic acetals have been reviewed ${ }^{1}$.

1,2:5,6-di-O-isopropylidene-D-mannitol (2) is a very important chiral template which has been used in the syntheses of numerous compounds ${ }^{2,3}$ where the first step is oxidative cleavage of the diol (2) either by sodium metaperiodate $^{4,5,6}$ or lead tetraacetate ${ }^{7}$ to afford 2,3-O-isopropylidene-Dglyceraldehyde (ㅁ) (Figure 1).

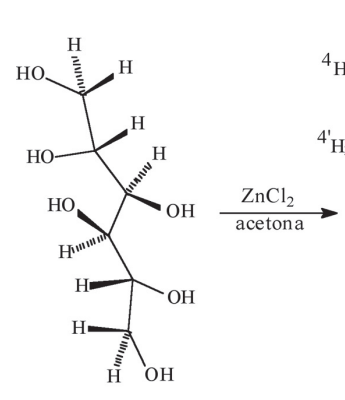

(1)

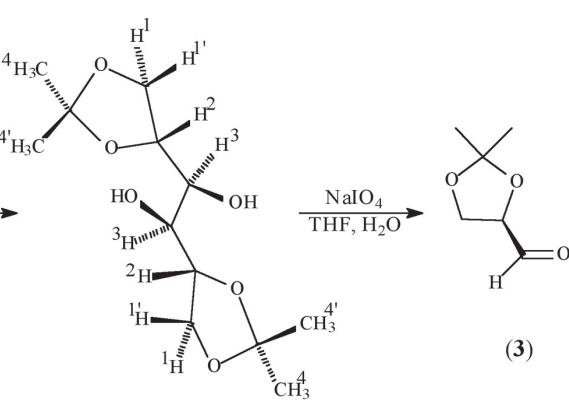

(2)
Figure 1: Synthesis of 2,3-O-isopropylidene-D-glyceraldehyde (ㄱ) $)$.

Selective acetalation of D-mannitol (1) with acetone in the presence of zinc chloride to give (2) was achieved by Baer, ${ }^{7,8}$ and was recently modified by Morpain et al. ${ }^{9}$. The yield in Baer's procedure not taking into account recovery of unreacted D-mannitol (1) was only $42 \%$ and that described by Morpain was $61 \%$.

The synthesis of 1,2:5,6-diacetone D-mannitol (2) employing D-mannitol and 2,2-dimethoxypropane in 1,2-dimethoxyethane under reflux and neutral conditions was performed in $52 \%{ }^{10}$. The use of tin chloride as catalyst in this reaction has not increased the yield significatively $y^{4,5,11}$.

Debost et al. ${ }^{12}$ has reacted D-mannitol (1), 2-methoxypropene and catalytic amounts of p-toluenesulphonic acid in N,N-dimethylformamide producing the diacetal (2) in $92 \%$ yield. Nevertheless two other research groups have repeated this procedure in yields of only $36-40 \%{ }^{13,14}$.

The aim of this work was prepare 1,2:5,6-di-O-isopropylidene-D-mannitol (2) in relatively large scales and high yield using cheap reagents, as it is routinely used in our research group in large quantities. We have obtained $300 \mathrm{MHz}{ }^{1} \mathrm{H}$ NMR and $75 \mathrm{MHz}{ }^{13} \mathrm{C}$ NMR spectra of the acetal and assigned all signals by double irradiation, difference NOE, and HETCOR spectra. So far the acetal (2) has been characterised in the literature by melting point, microanalysis ${ }^{8}$ and by preparing a derivative ${ }^{10,12}$. A high field NMR of (2) was recently described in the literature but the signals were not assigned ${ }^{4}$.

\section{EXPERIMENTAL}

Solvents and reagents were commercial products and were not purified. Acetone (analytical grade) was refluxed for $2 \mathrm{~h}$ in presence of anhydrous potassium carbonate protected against intrusion of moisture and distilled prior to use $\mathrm{e}^{15}$. The melting point was determined on a electrothermal digital apparatus without correction. Infrared spectra were recorded on a Perkin Elmer Spectrum 1000 grating spectrometer using potassium bromide disk scanning from 625 to $4000 \mathrm{~cm}^{-1}$. ${ }^{1} \mathrm{H}$ and ${ }^{13} \mathrm{C}$ NMR spectra were recorded in a Varian Mercury $(300 \mathrm{MHz})$ spectrometer. Tetramethylsilane $\left(\mathrm{SiMe}_{4}\right)$ was used as internal standard $(\Delta=0)$ and deuterated chloroform as solvent. GC-MS was conducted with a Shimadzu QP5050A gas chromatograph-mass spectrometer, using a glass capillary column $(25 \mathrm{~m} \times 0.25 \mathrm{~mm}) \mathrm{DB}-1$; The temperature was kept at $40^{\circ} \mathrm{C}$ for $5 \mathrm{~min}$. and raised at $4^{\circ} \mathrm{C} / \mathrm{min}$ from 80 to $285^{\circ} \mathrm{C}$; carrier gas, helio; inlet pressure $108.5 \mathrm{kPa}$. Mass spectra were obtained at $70 \mathrm{eV}$ electron energy and $3000 \mathrm{keV}$ multiplier-voltage.

Synthesis of 1,2:5,6-di-O-isopropylidene-D-mannitol.

A round bottomed flask containing zinc chloride (40 g, $293 \mathrm{mmol})$ was heated in open flame to melt the zinc chloride and remove any residual water. The flask was capped with a calcium chloride drying tube and cooled to room temperature. Anhydrous acetone $(400 \mathrm{~mL})$ was added to the reaction flask, stoppered and swirled to dissolve the solid. After the solution has cooled to room temperature, D-mannitol $(20 \mathrm{~g}, 110 \mathrm{mmol})$ was quickly added, the flask stoppered and the mixture stirred to a clear solution $(5 \mathrm{~h})$. The reaction mixture was poured onto a suspension of potassium carbonate $(45 \mathrm{~g})$ in water $(45 \mathrm{~mL})$, vigorously stirred, filtered and the zinc carbonate washed with acetone $(50$ $\mathrm{mL}$ ). The filtrate was concentrated with a flow of compressed air to remove acetone and most of the residual water. The white solid was dissolved in diethyl ether $(60 \mathrm{~mL})$ and transferred to a separating funnel. The organic layer was separated and the aqueous layer was extracted with diethyl ether $(3 \times 50 \mathrm{~mL})$. The combined organic layers was dried with anhydrous magnesium sulphate, filtered and washed with diethyl ether $(20 \mathrm{~mL})$. The solvent was removed under vacuum at room temperature to give a white slurry. Hexane $(100 \mathrm{~mL})$ was added to the slurry and stirred for $20 \mathrm{~min}$. The mixture was kept in the freezer at $-10^{\circ} \mathrm{C}$ for $1 \mathrm{~h}$ and in the refrigerator at $8^{\circ} \mathrm{C}$ for a further $1 \mathrm{~h}$. The mixture was filtered under vacuum and the solid washed with $100 \mathrm{~mL}$ of cold hexane. The combined white solid was left in the desiccator under vacuum for $2 \mathrm{~h}$ to give a white solid ( $25 \mathrm{~g}, 87 \%$ yield) containing (according to GC-MS) the diacetal (2) $(95 \%)$ and triacetal as impurity $(5 \%)$. This material is pure enough for most preparative purposes, but diacetal (2) free from triacetal may be obtained by stirring it in hexane for $30 \mathrm{~min}$. and filtering under vacuum.

The physical characteristics are as follows: Rf 0.2 (hexane/diethyl ether 1:1). m.p. $119-120{ }^{\circ} \mathrm{C}$ (lit. ${ }^{12} \mathrm{mp} 118-120 \mathrm{C}^{\circ}$ ); IR (KBr): 3403, 3280, 2991, 2934, 1159, 1069, 859, $846 \mathrm{~cm}^{-1} ;{ }^{1} \mathrm{H}-\mathrm{RMN}\left(300 \mathrm{MHz}, \mathrm{CDCl}_{3}\right) \Delta: 1.36(\mathrm{~s}, 6 \mathrm{H}$, $\mathrm{H} 4$ '), $1.42(\mathrm{~s}, 6 \mathrm{H}, \mathrm{H} 4), 2.66(\mathrm{~d}, 2 \mathrm{H}, \mathrm{OH}), 3.74\left(\mathrm{dd}, 2 \mathrm{H}, \mathrm{J}_{3, \mathrm{OH}}=6 \mathrm{~Hz}, \mathrm{~J}_{3,2}=5.7\right.$ 
$\mathrm{Hz}, \mathrm{H} 3), 3.98\left(\mathrm{dd}, 2 \mathrm{H}, \mathrm{J}_{1,2}=5.4 \mathrm{~Hz}, \mathrm{~J}_{\mathrm{gem}}=8.4 \mathrm{~Hz}, \mathrm{H1}\right.$ ), 4.09-4.22 (m, 4H, H1'and H2); ${ }^{13} \mathrm{C}-\mathrm{RMN}\left(75 \mathrm{MHz}, \mathrm{CDCl}_{3}\right) \Delta: 25.4$ (C4'), 26.9 (C4), 67.0 (C1), 71.3 (C3), $76.3(\mathrm{C} 2), 109.6\left[\underline{\mathrm{C}}\left(\mathrm{CH}_{3}\right)_{2}\right]$.

\section{RESULTS AND DISCUSSION}

D-mannitol (1), zinc chloride and anhydrous acetone were employed for the synthesis of (2) in $87 \%$ yield in scales varying from $1 \mathrm{~g}$ up to $30 \mathrm{~g}$ of $\mathrm{D}$-mannitol (1). After $5 \mathrm{~h} \mathrm{D}$-mannitol (1) goes into solution (even when the reaction is performed with $30 \mathrm{~g}$ of D-mannitol), which is a clear indication of acetal formation. The reaction did not go to completion when two molar equivalents of zinc chloride was employed (2.7 molar excess was used).

Starting D-mannitol (1) is left after reaction work up due to acetal (2) hydrolysis when water is removed under vacuum at $40{ }^{\circ} \mathrm{C}$. Hydrolysis was avoided by evaporating most of the water content by a flow of compressed air. The white slurry was transferred to a separating funnel and extracted three times with diethyl ether, and the combined organic layers was dried with anhydrous magnesium sulfate. The volatile diethyl ether was evaporated in the rotary evaporator without heating and the white residue was washed with hexane resulting in the diacetal (2) (87\% yield). TLC, GC-MS, ${ }^{1} \mathrm{H}$ and ${ }^{13} \mathrm{C}$ NMR showed that the white solid presented a very minor amount of the less polar triacetal (5\%). It has been used without any further purification, for the synthesis of 2,3-O-isopropylidene-Dglyceraldehyde $(\underline{3})^{2,3}$. Nevertheless we managed to obtain the diacetal pure by successive hexane washing. Table 1 presents the procedures found in the literature for the synthesis of diacetal (2) and their respective yields.

Table 1: Synthesis of 1,2:5,6-di- $O$-isopropylidene-D-mannitol described in the literature.

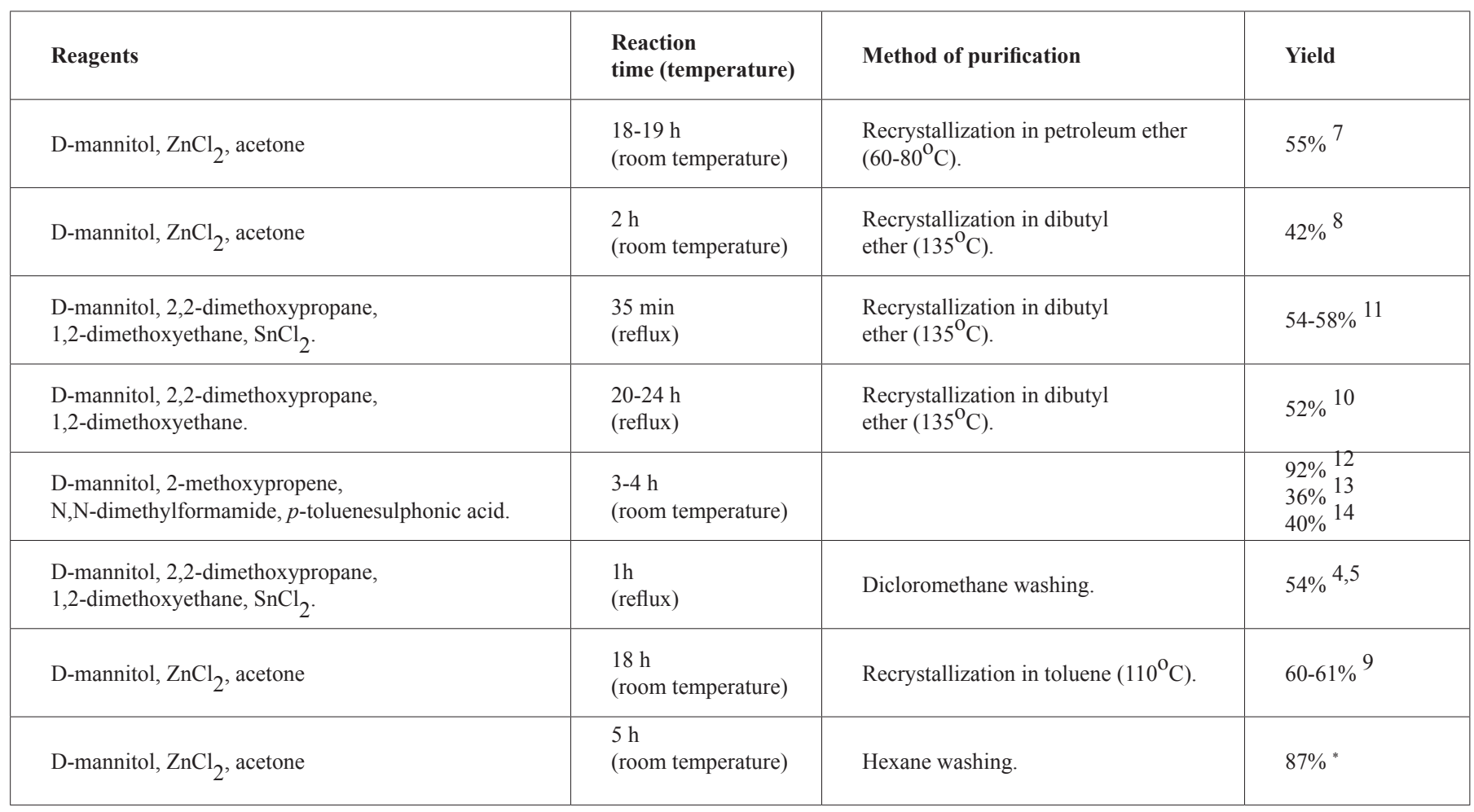

* described in this work.

The acetal (2) stability was tested by dissolving three samples $(200 \mathrm{mg})$ in diethyl ether, acetone and dichloromethane and left at room temperature $(25$ $\left.{ }^{\circ} \mathrm{C}\right)$. We observed no signs of decomposition even after 30 days for the ether and acetone solution; however the dichloromethane solution became cloudy after 3 days, which is a clear indication of decomposition. The instability of the latter solution can be explained by the acidity of dichloromethane which hydrolyses the acetal $(\underline{\mathbf{2}})$ protecting group back to the insoluble D-mannitol $(\underline{\mathbf{1}})$.

Elucidation for the previous works' lower yields (yields from 42 to $61 \%$ ) $^{7,8,9}$ was carried out by heating the acetal $(\underline{\mathbf{2}})$ in either hexane or water in a water bath at $40{ }^{\circ} \mathrm{C}$. We have observed about $50 \%$ decomposition of the acetal even after 5 min. of heating. Therefore this should be one of the reasons for the literature lower yields as it was common practice refluxing the acetal in petroleum ether, dibutyl ether and toluene during the recrystallization (table 1).

The formation of the diacetal is inferred from the ${ }^{1} \mathrm{H}$ NMR signals in $\delta$ 1.36 and 1.42 each one integrating for 6 hydrogens $\left(2 \times \mathrm{CH}_{3}\right)$ and a doublet in $\delta 2.66$ integrating for 2 hydrogens $(2 \mathrm{x} \mathrm{OH})$. Decoupling the doublet of doublets at $\delta 3.75$ causes the doublet at $\delta 2.66$ to collapse to a singlet and modifies in some way the multiplet at $\delta 4.13-4.23$. The doublet of doublets at $\delta 3.75$ was assigned to $\mathrm{H} 3$ since we identified the doublet at $\delta 2.66$ as the $\mathrm{OH}$. Decoupling the multiplet at $\delta$ 4.13-4.23 causes the doublet of doublets at $\delta$ 3.90 to simplify to a distorted singlet and the doublet of doublets at $\delta 3.75$ to collapse to a doublet. The signal at $\delta 3.90$ becomes a distorted singlet because of the proximity of the signal irradiated. Decoupling of the doublet at $\delta 2.66$ $(\mathrm{OH})$ collapses the doublet of doublets at $\delta 3.75$ to a doublet. This confirms the assignment of the signal in $\delta 3.75$ to H3. The multiplet in $\delta$ 4.13-4.23 should therefore be $\mathrm{H} 1$ ' and $\mathrm{H} 2$ and the doublet of doublets at $\delta 3.90$ should be $\mathrm{H} 1$. The complete assignment of H1', H1 and the methyl groups were obtained by NOE difference spectra. Irradiation at $\delta 1.35\left(\mathrm{CH}_{3}\right)$ strongly enhances $\mathrm{H} 1$ ' and $\mathrm{H} 2(1.54 \%)$. As the relative and absolute stereochemistry of $\mathrm{H} 1$ ' and $\mathrm{H} 2$ is determined by the chiral starting material $(\underline{\mathbf{1}})$ the relative position of the methyl was determined as $\mathrm{H}^{\prime}$ '. Irradiation at $\delta 1.42\left(\mathrm{CH}_{3}\right)$ enhances $\mathrm{H} 1(0.41 \%)$ and H3 $(0.57 \%)$, therefore assignment of this signal should be H4. The HETCOR experiment was run to undoubtedly make all assignments and especially to confirm the assignments in $\delta 25.4$ and 26.9 to C4' and C4 respectively. 


\section{CONCLUSIONS}

This work describes the synthesis in $87 \%$ yield of the important chiral precursor $(\underline{\mathbf{2}})$ employing cheap and readily available reagents. Simple stability tests showed that the success of our procedure is connected with the care taken in avoiding the heating during the reaction work up and product purification.

High field NMR spectra were obtained and assignment of all signals was accomplished with the aid of double irradiation, difference NOE and HETCOR spectra.

\section{ACKNOWLEDGEMENTS}

We would like to thank FAPEMIG (Minas Gerais - Brazil) for the research support and $\mathrm{CNPq}$ (Brazilian council) for the grants of FOS, WAS and VMTC.

\section{REFERENCES}

1. D. M. Clode, Chem. Rev., 79, 491 (1979).

2. E. S. de Alvarenga, J. Mann, J. Chem. Soc. Perkin Trans., 1, 2141 (1993).

3. E. S. de Alvarenga, C. J. Cardin, J. Mann, Tetrahedron, 53, 1457 (1997).

4. C. R. Schmid, J. D. Bryant, M. Dowlatzedah, J. L. Phillips, D. E. Prather, R. D. Schantz, N. L. Sear, C. S. Vianco, J. Org. Chem., 56, 4056, (1991).

5. C. R. Schmid, J. D. Bryant, Org. Syn., 72, 6, (1993).

6. J. Mann, N. K. Partlett, A. Thomas, J. Chem. Research (S), 137, 369 (1987).

7. E. Baer, H. O. L. Fischer, J. Biol. Chem.,128, 463 (1939).

8. E. Baer, J. Am. Chem.Soc.,67, 338 (1945).

9. C. Morpain, B. Nasser, B. Laude, N. Latruffe, Organic Preparation Procedures International, 22, 540 (1990).

10. G. J. F. Chittenden, Carbohydr. Res., 87, 219, (1980).

11. G. J. F. Chittenden, Carbohydr. Res., 84, 350 (1980).

12. J. L. Debost, J. Gelas, D. Horton, J. Org. Chem., 48, 1381 (1983).

13. J. Kuszmann, E. Tomori, I. Meerwald, Carbohydr. Res., 128, 87 (1984).

14. G. J. F Chittenden, Carbohydr. Res., 222, 283 (1991).

15. D. D. Perrin, W. L. F Armarego, Purification of Laboratory Chemicals, Pergamon, Oxford, UK, 3rd edn., p 68, (1988). 